\title{
Pengembangan Web Service Sistem Informasi Boarding School
}

\author{
Aniqoh Bachriwindi', M. Robih Thuluz Zaman², Muhammad Naufal Firdaus ${ }^{3}$, Muhammad \\ Ainul Yaqin 4 \\ Jurusan Teknik Informatika, Fakultas Sains dan Teknologi \\ Universitas Islam Negeri Maulana Malik Ibrahim Malang \\ Jalan Gajayana No. 50 Malang 651544 Telp. +62 (341) 551-354 \\ 16650015@student.uin-malang.ac.id,16650012@student.uin-malang.ac.id, \\ 16650013@student.uin-malang.ac.id,yaqinov@ti.uin-malang.ac.id
}

\begin{abstract}
The boarding school information system is a system that provides information to support the operational, management, and decision making functions of an organization. Information sources within the information system that support day-to-day management operations such as transaction processing, status clarification, and so on. Boarding school information systems generally consist of a variety of systems, including welfare systems, management, premises, procedures and policies, and staffing. With a variety of systems in a boarding school information system, it is necessary to integrate between systems that aim to avoid data duplication in each system and increase system flexibility which can be achieved by utilizing web service technology. The purpose of this study is to design a web service on boarding school information systems that conform to 52 boarding school minimum standards set by the Welsh Assembly Government. The results of the development of an information system web service design is to map class diagrams that will be made on the web service design.
\end{abstract}

Keywords: Web service, Information system, Welsh Assembly Government

\section{Abstrak}

Sistem informasi boarding school merupakan sistem yang menyediakan informasi untuk mendukung kegiatan operasional, manajemen, dan fungsi pengambilan keputusan dari suatu organisasi. Sumber informasi yang ada di dalam sistem informasi tersebut yang mendukung operasi manajemen sehari-hari seperti pengolahan transaksi, penjelasan status, dan lain sebagainya. Sistem informasi boarding school secara umum terdiri dari berbagai macam sistem, diantaranya seperti sistem kesejahteraan, manajemen, premis, prosedur dan kebijakan, serta staffing. Dengan adanya berbagai system dalam sebuah sistem informasi boarding school, maka perlu adanya integrasi antar sistem yang bertujuan untuk menghindari adanya duplikasi data di setiap sistem dan meningkatkan fleksibilitas sistem yang mana hal itu bisa dicapai dengan memanfaatkan teknologi web service. Tujuan penelitian ini adalah merancang web service pada sistem informasi boarding school yang sesuai dengan Standar 52 standar minimum boarding school yang telah ditetapkan Oleh Welsh Assembly Goverment. Hasil pengembangan rancangan web service sistem informasi yaitu dengan memetakan class diagram yang akan dibuat pada perancangan web service.

Kata kunci: Web service, Sistem informasi, Welsh Assembly Goverment

\section{PENDAHULUAN}

Penggunaan teknologi pada era modern ini memang sudah menjadi sebuah kebutuhan yang tidak terelakkan lagi. Hal ini terjadi pada semua instansi, termasuk boarding school. Boarding school merupakan lembaga pendidikan agama islam yang diperkenalkan oleh wali sembilan di Jawa sekitar lima ratus tahun yang lalu. Sejak saat itu, lembaga boarding school telah mengalami perubahan-perubahan dan telah masuk ke dalam berbagai macam peran pada kemasyarakatan Indonesia [1]. 
Boarding school adalah sebuah pendidikan tradisional yang para siswanya tinggal dan belajar dibawah bimbingan guru atau lebih dikenal dengan sebutan kiai. Dalam boarding school biasanya mempunyai sistem mengajar yang berbeda. Pada masa saat ini, sistem yang digunakan oleh boarding school sudah bergeser mengikuti zaman menjadi lebih modern. Terlebih lagi saat ini sudah ada standar- standar yang menjadi acuan dalam mengelola boarding school sehingga menjadikan boarding school di Indonesia lebih maju.

Informasi mengenai boarding school juga dibutuhkan secara cepat dan akurat. Sedangkan pada realita sistem informasi boarding school belum dikelola dengan baik oleh pihak boarding school. Baik itu mengenai pengolahan dan penanganan data secara manual, pencarian data yang masih konvensional. Dalam pengolahan data dan penangannya, dibutuhkan beberapa integrasi antar sistem informasi. Oleh karena itu, dibuat perancangan web service sistem informasi boarding school dengan integrasiintegrasi internal.

Dengan melihat latar belakang di atas, maka dapat diidentifikasikan beberapa rumusan masalah adalah bagaimana membuat rancangan web service sistem informasi boarding school. Tujuan penelitian diperlukan agar dapat terukur dan terperinci sesuai dengan kebutuhan. Tujuan dari penelitian ini adalah menyajikan rancangan web service sistem informasi boarding school, dan mempermudah integrasi sistem yang ada.

\section{METODOLOGI PENELITIAN}

\subsection{Boarding school}

Lembaga Pendidikan mengenal Pesantren sebagai Lembaga Pendidikan Islam yang di dalamnya terdapat proses belajar mengajar agama Islam dan sebagai media untuk menyebarkan ilmu agama. Pesantren mempunyai sistem pendidikan tersendiri [2]. Pesantren mulanya tersebar hanya di beberapa pedesaan namum, seiring berkembangnya zaman, pesantren mengalami modernisasi. Pesantren dulunya hanya sebagai tempat tinggal yang digunakan untuk menimba ilmu dengan cara berdekatan dengan sang pengajar atau kyai, sekarang pesantren dianggap sebagai lembaga pendidikan yang mencakup ruang lingkup yang kompleks, untuk memenuhi standart nasional boarding school, butuh beberapa proses pengembangan arsitektur data sistem informasi boarding school agar menjadi lembaga pendidikan islam yang memadai.

\subsection{Sistem Informasi}

Definisi dari sistem informasi adalah sebuah sistem buatan manusia yang terdapat berbagai komponen dalam suatu organisasi dan bertujuan untuk menyajikan informasi [3]. Dapat disimpulan sistem informasi adalah sebuah software, hardware, data dan jaringan komunkasi yang terorganisasi untuk mengumpulkan, memasukkan, mengolah, mengendalikan, menyimpan data dan melaporkan infromasi untuk dapat mendukung pengambilan keputusan atau tujuan suatu organisasi tersebut. 


\subsection{Web Service}

Web Service adalah antar muka yang mendeskripsikan koleksi yang dapat diakses dalam jaringan menggunakan format standar XML untuk pertukaran pesan [4]. Web service juga tidak terikat kepada bahasa pemrograman atau sistem operasi tertentu. Selain format standar XML, pertukaran data juga dapat menggunakan JSON.

\section{a. Arsitektur Web Service}

Service Oriented Architecure (SOA) mendeskripsikan tiga peranan yang berbeda dimana pada setiap peran menunjukkan peran dari masing-masing entitas yang ada pada sistem. Secara umum, web service memiliki tiga komponen yang terlibat di dalamnya, yaitu service provider, service registry dan service requestor. Service provider adalah penyedia layanan. Service registry bertugas untuk menerbitkan setiap layanan yang ada pada service provider. Service requestor melihat layanan yang disediakan di service registry. Service requestor akan meminta layanan ke service provider berdasarkan layanan yang diinginkan, lalu service provider memberikan hasil permintaan layanan ke service requestor.

\section{b. Extensible Markup Language (XML)}

XML merupakan bahasa yang digunakan dalam menciptakan dokumen yang mana komputer dan manusia dapat membaca dokumen tersebut dengan mudah. Web service dapat saling berkomunikasi dengan memanfaatkan XML, karena XML disajikan dalam bentuk teks sehingga mudah untuk ditransportasikan menggunakan protocol HTTP. XML bersifat platform independent sehingga informasi di dalamnya dapat dibaca oleh aplikasi dan platform yang berbeda asalkan aplikasi yang berkomunikasi tersebut mampu membaca tag-tag XML [5].

\section{c. SOAP}

SOAP (Simple Object Access Protocol) merupakan sebuah standar format dokumen dalam bentuk dokumen XML yang digunakan untuk proses request dan response antara web service dengan aplikasi yang memanggilnya [5]. Dokumen SOAP yang dipergunakan untuk melakukan request disebut SOAP request, sedangkan dokumen SOAP yang diperoleh dari web service disebut SOAP response. SOAP memungkinkan beberapa aplikasi meskipun aplikasi tersebut menggunakan bahasa pemrograman yang berbeda dan dijalankan pada platform yang berbeda. Struktur SOAP terdiri atas SOAP envelope, SOAP header, SOAP body dan SOAP Fault.

\section{d. WDSL}

WSDL (Web Service Description Language) adalah sebuah dokumen XML yang menjelaskan informasi lengkap mengenai operasi-operasi yang ada pada sebuah web service. WSDL menjelaskan semua informasi yang berkaitan dengan layanan yang disediakan oleh web service baik itu berupa parameter-paremeter yang diperlukan untuk memanggil sebuah method, dan tipe data yang dikembalikan oleh method yang dipanggil tersebut. Setiap layanan yang ada pada web service dapat dideskripsikan dengan menggunakan elemen XML pada dokumen WSDL. 


\section{e. TOGAF}

TOGAF merupakan sebuah kerangka terperinci dan sekumpulan perangkat pendukung untuk mengembangkan sebuah arsitektur teknologi informasi. Kerangka menyediakan sebuah klasifikasi untuk menghubungkan konsep-konsep yang menggambarkan dunia nyata pada konsep system informasi dan implementasinya. Kerangka digunakan untuk menjelaskan keseluruhan perusahaan dan untuk menyimpan informasi tersebut, biasanya didukung oleh perangkat tempat penyimpanan yang tepat. ADM merupakan metode generik yang berisikan sekumpulan aktivitas yang digunakan dalam memodelkan pengembangan arsitektur enterprise. Metode ini juga dibisa digunakan sebagai panduanatau alat untuk merencanakan, merancang, mengembangkan dan mengimplementasikan arsitektur sistem informasi untuk organisasi [6].

\subsection{Metode Penelitian}

Data-data yang dibutuhkan dalam penelitian ini adalah standar minimum boarding school. standar tersebut dibuat oleh Welsh Assembly Goverment Kementrian kesehatan dan pelayanan sosial pada tahun 2003 sebanyak 52 standar. peneliti menggunakan 52 standar tersebut untuk memetakan class diagram yang akan dibuat pada perancangan web service Boarding school. Berikut 52 standar minimum Boarding school yang telah ditetapkan Oleh Welsh Assembly Goverment pada tahun 2003

1. Pernyataan prinsip dan praktik asrama

2. Antisipasi bulliying

3. Membuat komite perlindungan anak

4. Adanya tata tertib dan peraturan

5. Kritik dan saran dari wali santri

6. UKS

7. Catatan kesehatan

8. Kepengurusan asrama

9. Kesiapan menghadapi ancaman insiden

10. Placement kamar sesuai gender dan umur

11. Kegiatan ekstra

12. Kritik dan saran dari civitas

13. Adanya ketua kamar

14. Adanya pendamping kamar oleh pengurus

15. Pertolongan pertama medis/P3k

16. Pemeriksaan kesehatan santri

17. Bimbingan konseling kesehatan

18. Semua santri mendapatkan hak yang sama rata

19. Kontak wali santri

20. Keamanan barang pribadi santri

21. Asrama lama membimbing asrama baru

22. Adanya wali kelas

23. Monitoring ketertiban dan keamanan

24. Catering

Pengembangan Web Service Sistem Informasi Boarding School (Aniqoh Bachriwindi)|39 
25. Minuman dan makanan ringan (kantin)

26. Pencegahan dan antisipasi kebakaran

27. Perlindungan nama baik asrama

28. Akomodasi santri oleh pengurus saat kegiatan diluar area asrama

29. Pengawasan mengenai kegiatan yang memiliki resiko

30. Akses informasi dan fasilitas luar asrama

31. Pengawasan santri oleh pengurus

32. Pengasawan santri saat meninggalkan asrama

33. Keamanan jam malam

34. Pelatihan kepengurusan mengenai jobdesc

35. Asrama mengikuti aturan yang jelas

36. Adanya hubungan antara pengurus dan santri

37. Memberi ruang privasi untuk santri

38. Perekrutan kepengurusan

39. Pengawasan kunjungan orang tua dan barang kiriman untuk santri

40. Sarana prasarana

41. Keamanan akomodasi dan akses publik

42. Perlengkapan kamar santri sesuai dengan kebutuhan

43. Fasilitas asrama tidak boleh dibawa ke luar

44. Fasilitas toilet dan tempat cuci

45. Fasilitas ruang ganti

46. Area rekreasi asrama (indoor/outdoor)

47. Keamanan area rekreasi

48. Akomodasi untuk santri yang sakit

49. Loundry

50. Alat tulis dan barang pribadi santri

51. Pemeriksaan kamar santri sebelum ditempati

52. Study banding asrama

\subsection{Pengumpulan Data}

Teknik pengumpulan dilakukan dengan cara studi literatur sebuah standar yang dibuat oleh Welsh Assembly Goverment Kementrian kesehatan dan pelayanan sosial inggris untuk boarding school.

\subsection{Instrumen Pengumpulan Data}

Adapun beberapa instrumen pengumpulan data yang dilakukan pada perancangan web service boarding school antara lain sebagai berikut:

a. Menentukan ruang lingkup penelitian.

b. Menentukan fokus penelitian.

c. Menentukan objek penelitian

d. Membuat Jadwal Penelitian

e. Melakukan penelitian

f. Menganalisis data yang terkumpul 


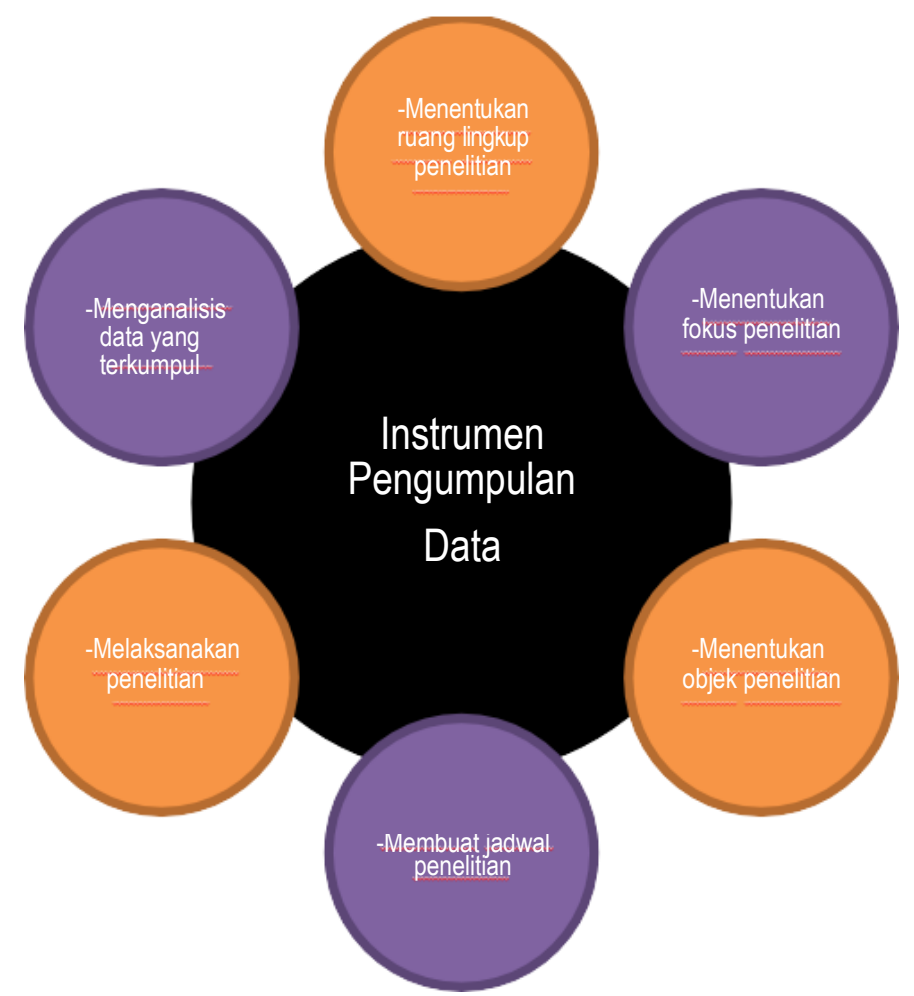

Gambar 1. Instrumen Pengumpulan Data

\section{HASIL DAN PEMBAHASAN}

\subsection{Tahap Perencanaan}

Perancangan sistem dilakukan dengan merancang web service pada sistem informasi boarding school dalam bentuk class diagram. Rancangan sistem bertujuan untuk membangun sistem informasi boarding school untuk memenuhi 5 kebutuhan, yaitu prosedur dan kebijakan kesejahteraan, organisasi dan manajemen, dukungan kesejahteraan santri, premis dan staffing.

\subsection{Tahap Analisis Kebutuhan}

Kebutuhan yang di analisis berupa analisis modul - modul sistem pada pengembangan rancangan web service sistem informasi boarding school yang sesuai dengan 52 standar minimum Boarding school yang telah ditetapkan Oleh Welsh Assembly Goverment pada tahun 2003.

\subsection{Tahap perancangan sistem}

Perancangan sistem dilakukan dengan merancang arsitektur web service pada sistem informasi boarding school yang berbentuk class diagram. Perancangan sistem pada proses ini bertujuan untuk memenuhi kebutuhan dan proses yang terdapat di standar nasional pendidikan. Sistem informasi boarding school yang ideal meliputi sistem dukungan kesejahteraan, organisasi manajemen, premis, prosedur dan kebijakan dan staffing yang masing-masing di setiap sistem itu menjalankan fungsinya untuk memenuhi segala kebutuhan di boarding school. Berikut ini merupakan rancangan web service dalam bentuk class diagram. 
Jurnal Riset Sistem Informasi Dan Teknik Informatika (JURASIK)

Volume 5 Nomor 1 Februari, pp 36-49

ISSN: 2527-5771/EISSN: 2549-7839

http://tunasbangsa.ac.id/ejurnal/index.php/jurasik

\section{a. Dukungan kesejahteraan}

Dukungan

Kesejahteraan Santri
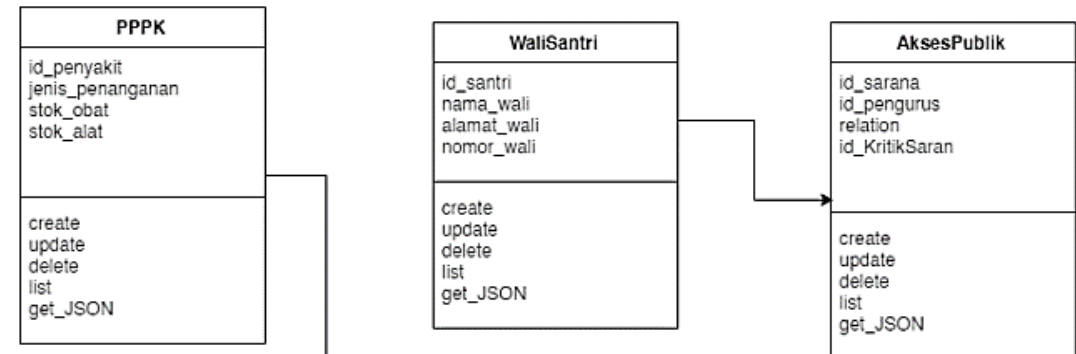

\begin{tabular}{|l|}
\hline \multicolumn{1}{|c|}{ KesiapanInsiden } \\
\hline $\begin{array}{l}\text { jenis_insiden } \\
\text { jenis_antisipasi }\end{array}$ \\
\hline $\begin{array}{l}\text { create } \\
\text { update } \\
\text { delete } \\
\text { list } \\
\text { get_JSON }\end{array}$ \\
\hline
\end{tabular}
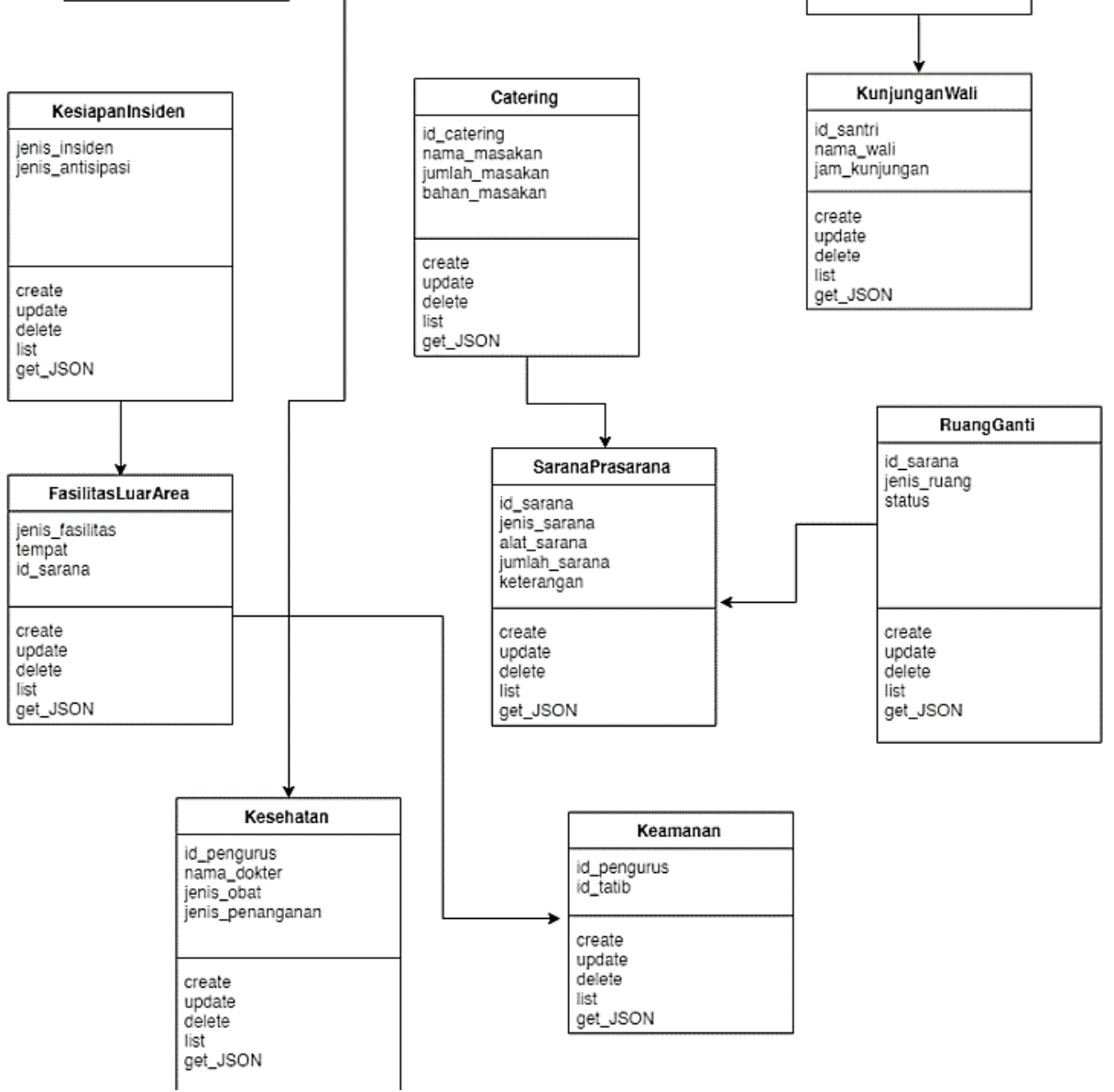

Gambar 2. Class diagram dukungan kesejahteraan santri

Dukungan kesejahteraan santri meliputi beberapa entitas seperti kunjungan wali, katering, kesehatan hingga keamanan. 
Jurnal Riset Sistem Informasi Dan Teknik Informatika (JURASIK)

Volume 5 Nomor 1 Februari, pp 36-49

ISSN: 2527-5771/EISSN: 2549-7839

http://tunasbangsa.ac.id/ejurnal/index.php/jurasik

\section{b. Organisasi Manajemen}

organisasi dan

manajemen

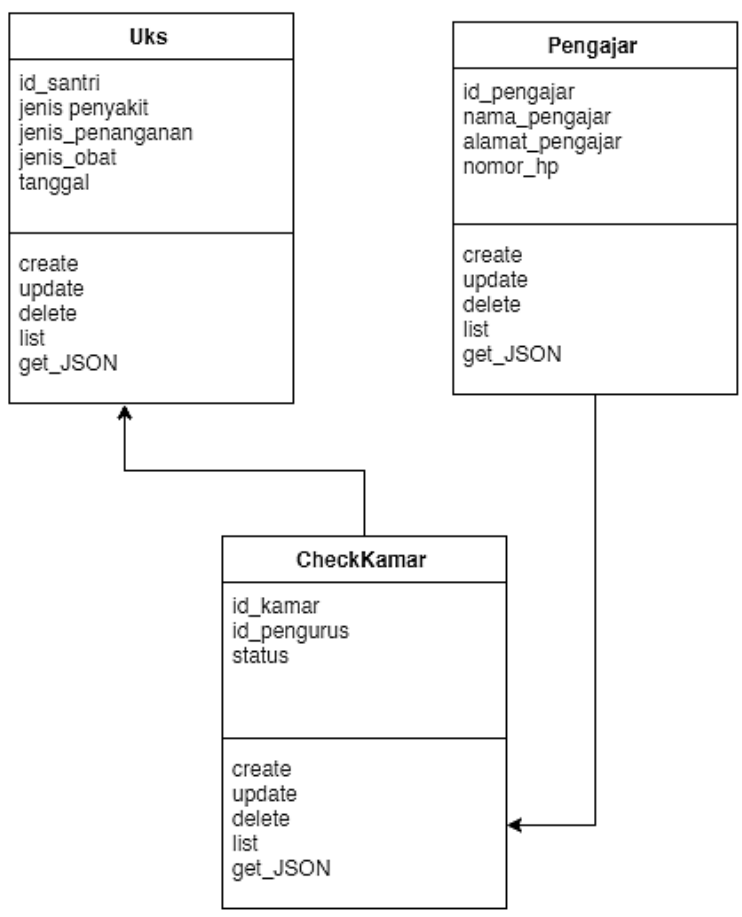

Gambar 3. Class diagram bagian organisasi manajemen

Organisasi dan manajemen meliputi kepengurusan UKS, pengajar, serta pengecekan kamar bagi santri baru. 
Jurnal Riset Sistem Informasi Dan Teknik Informatika (JURASIK)

Volume 5 Nomor 1 Februari, pp 36-49

ISSN: 2527-5771/EISSN: 2549-7839

http://tunasbangsa.ac.id/ejurnal/index.php/jurasik

\section{c. Premis}

Premis

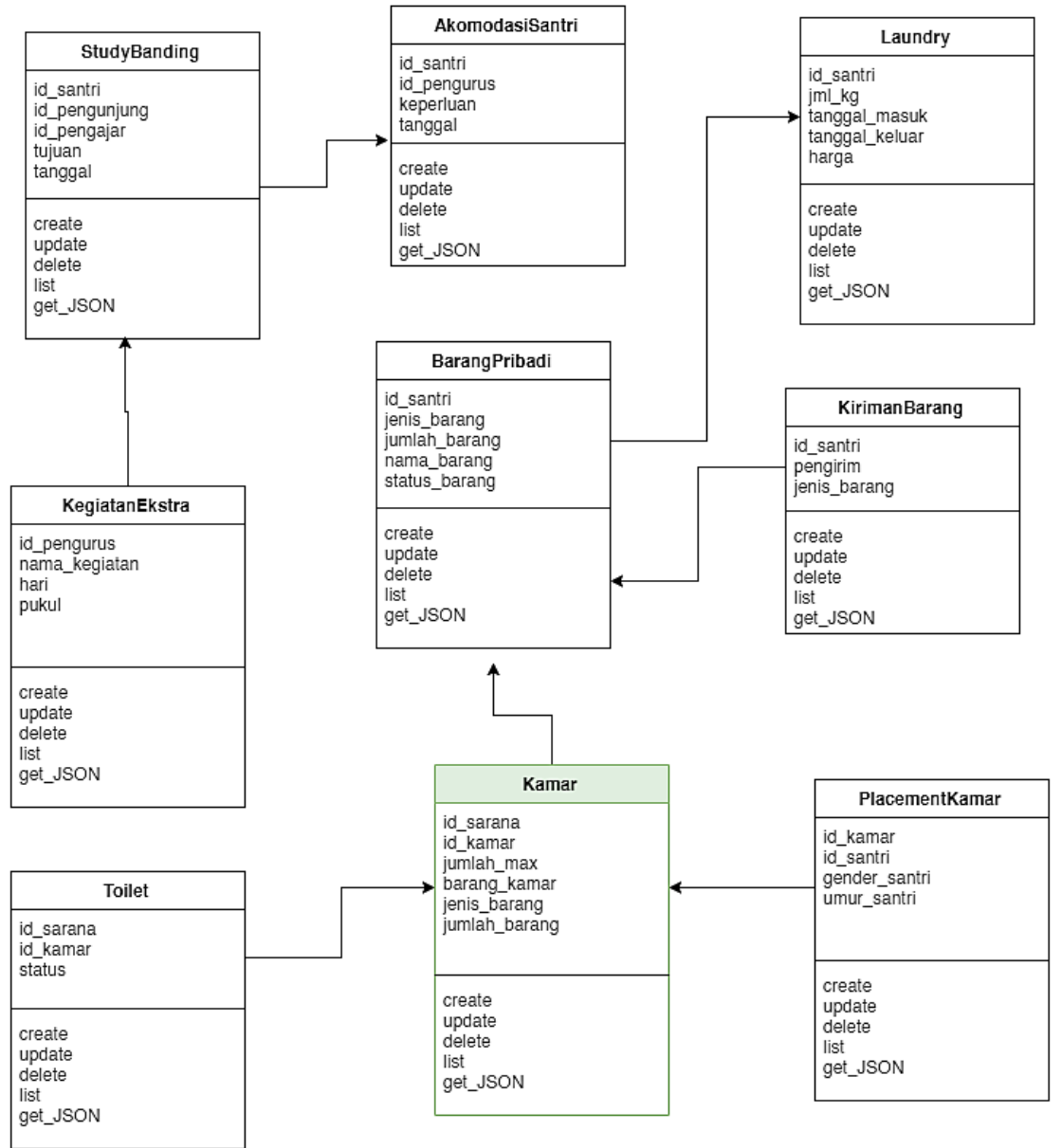

Gambar 4. Class diagram bagian premis

Bagian ini sebagai penunjang kebutuhan santri seperti laundry, pengiriman barang dan penempatan kamar. 
Jurnal Riset Sistem Informasi Dan Teknik Informatika (JURASIK)

Volume 5 Nomor 1 Februari, pp 36-49

ISSN: 2527-5771/EISSN: 2549-7839

http://tunasbangsa.ac.id/ejurnal/index.php/jurasik

\section{d. Prosedur dan Kebijakan}

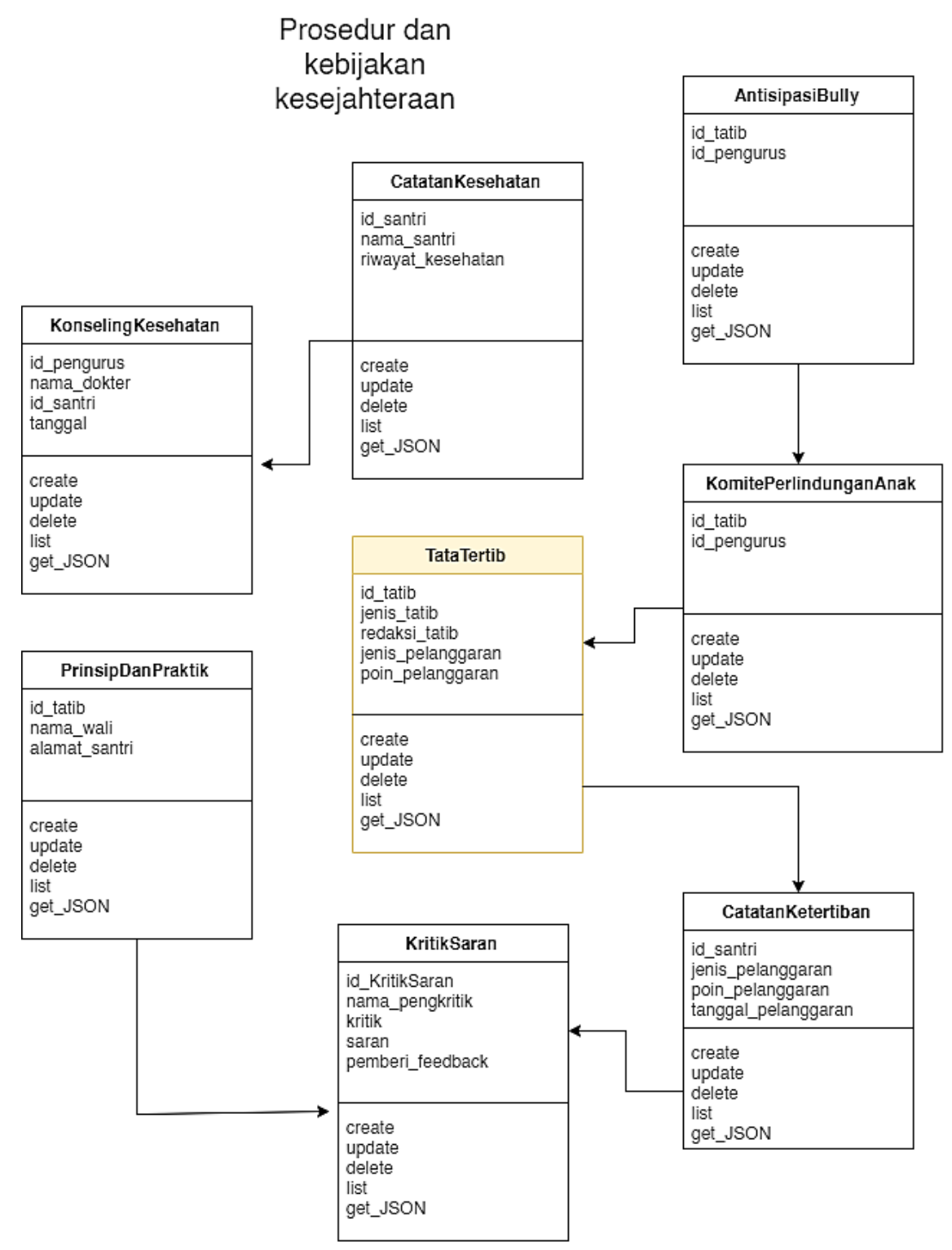

Gambar 5. Class diagram bagian prosedur dan kebijakan.

Pada rancangan prosedur dan kebijakan terdapat berbagai macam entitas yang akan digunakan, diantaranya manajemen kebijakan, ketertiban hingga kritik dan saran. 
Jurnal Riset Sistem Informasi Dan Teknik Informatika (JURASIK)

Volume 5 Nomor 1 Februari, pp 36-49

ISSN: 2527-5771/EISSN: 2549-7839

http://tunasbangsa.ac.id/ejurnal/index.php/jurasik

\section{e. Staffing}

\section{Staffing}
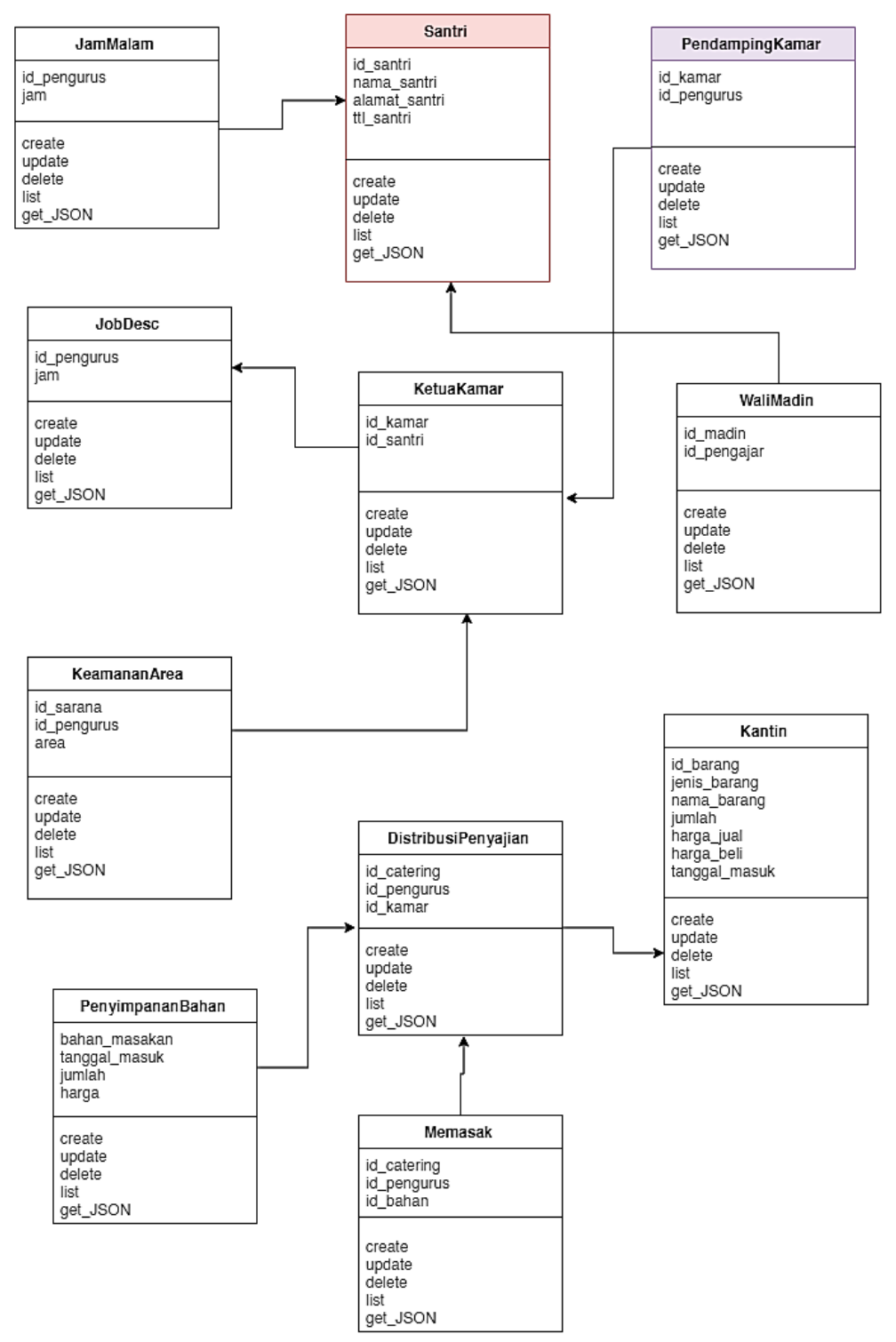

Gambar 6. Class Diagram bagian staffing

Pada bagian ini mencakup seluruh proses yang berkaitan dengan kepengurusan santri seperti ketua kamar, pendamping kamar, jam malam hingga distribusi makanan. 


\subsection{Modul modul di dalam sistem}

Dari keseluruhan rancangan yang telah dibuat terdapat beberapa modul yang dapat diintegrasikan satu sama lain, yaitu:

a) Bagian dukungan dan kesejahteraan santri, yaitu manajemen sarana prasarana, akses publik, kesehatan, keamanan hingga fasilitas luar area.

b) Bagian organisasi manajemen yaitu organisasi uks, penentuan pengajar dan pengecekan kamar oleh pengurus bagi santri baru.

c) Bagian premis yaitu, akomodasi santri, laundry, kiriman barang, studi banding dan kegiatan ekstra.

d) Bagian prosedur dan kebijakan yaitu, tata tertib, catatan kesehatan, prinsip dan praktik, konseling kesehatan dan kritik saran.

e) Bagian staffing yaitu, jam malam, santri, ketua kamar, pendamping kamar, wali madin dan kemanan area.

\subsection{Tahap Implementasi}

\section{a) Sistem Informasi kesejahteraan}

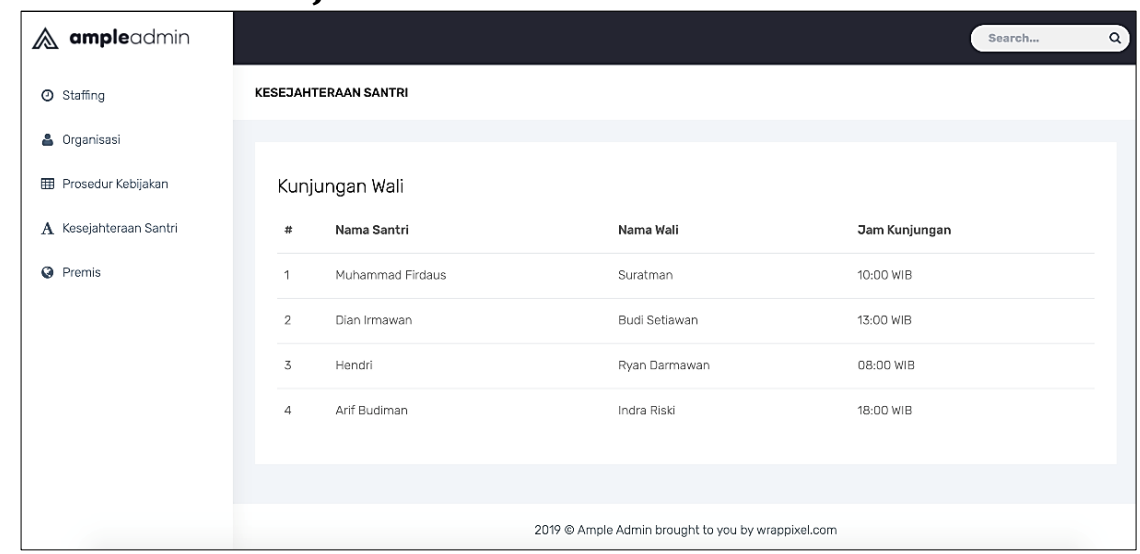

Gambar 7. Tampilan prototype kesejahteraan

b) Sistem Informasi Organisasi Manajemen

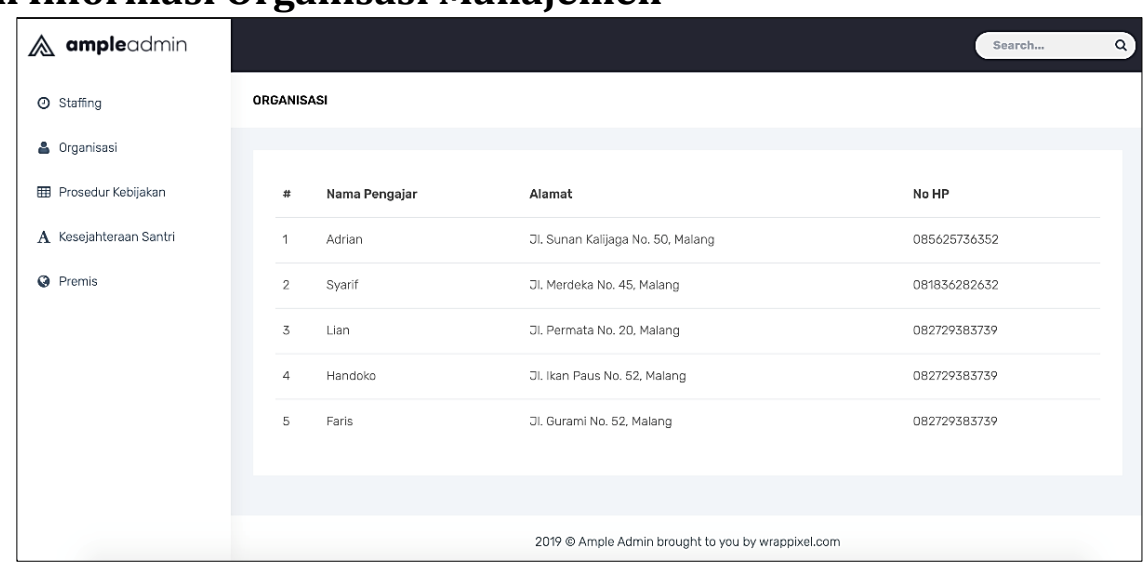

Gambar 7. Tampilan prototype organisasi manajemen 
Jurnal Riset Sistem Informasi Dan Teknik Informatika (JURASIK)

Volume 5 Nomor 1 Februari, pp 36-49

ISSN: 2527-5771/EISSN: 2549-7839

http://tunasbangsa.ac.id/ejurnal/index.php/jurasik

c) Sistem Informasi Premis

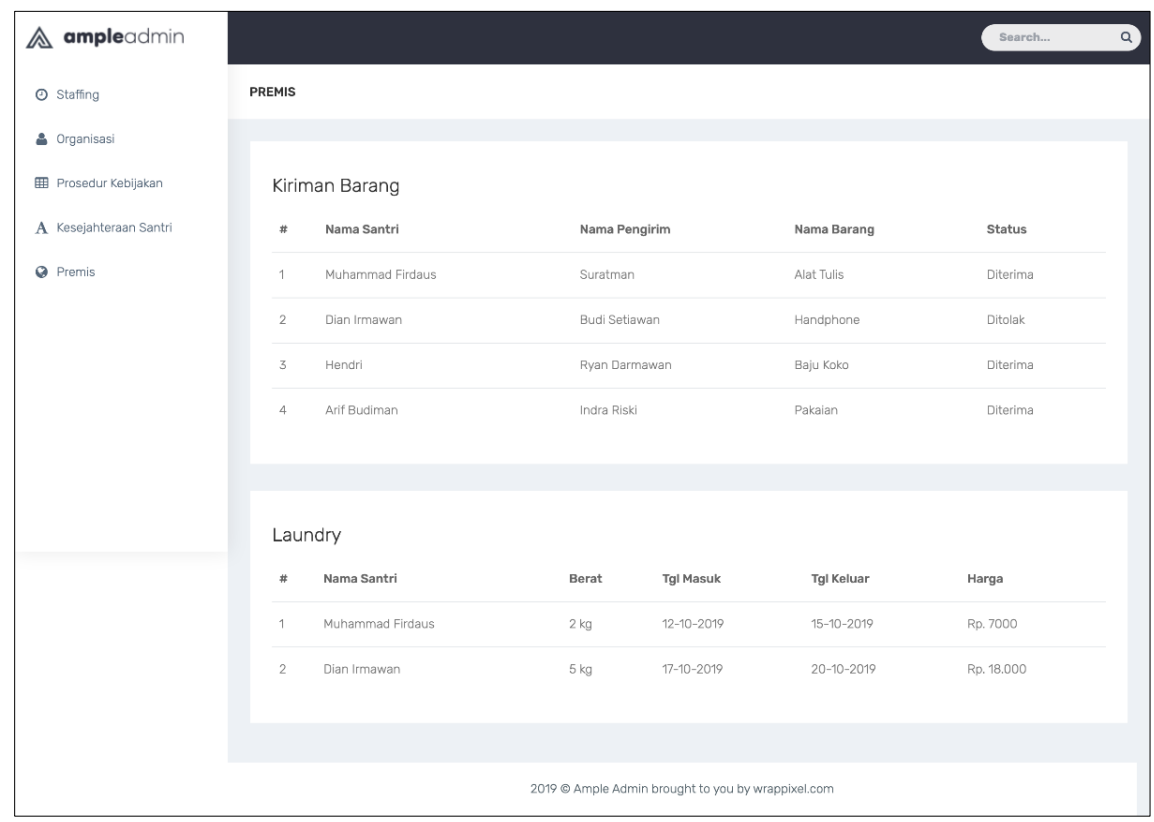

Gambar 8. Tampilan prototype premis

\section{d) Sistem Informasi Prosedur dan Kebijakan}

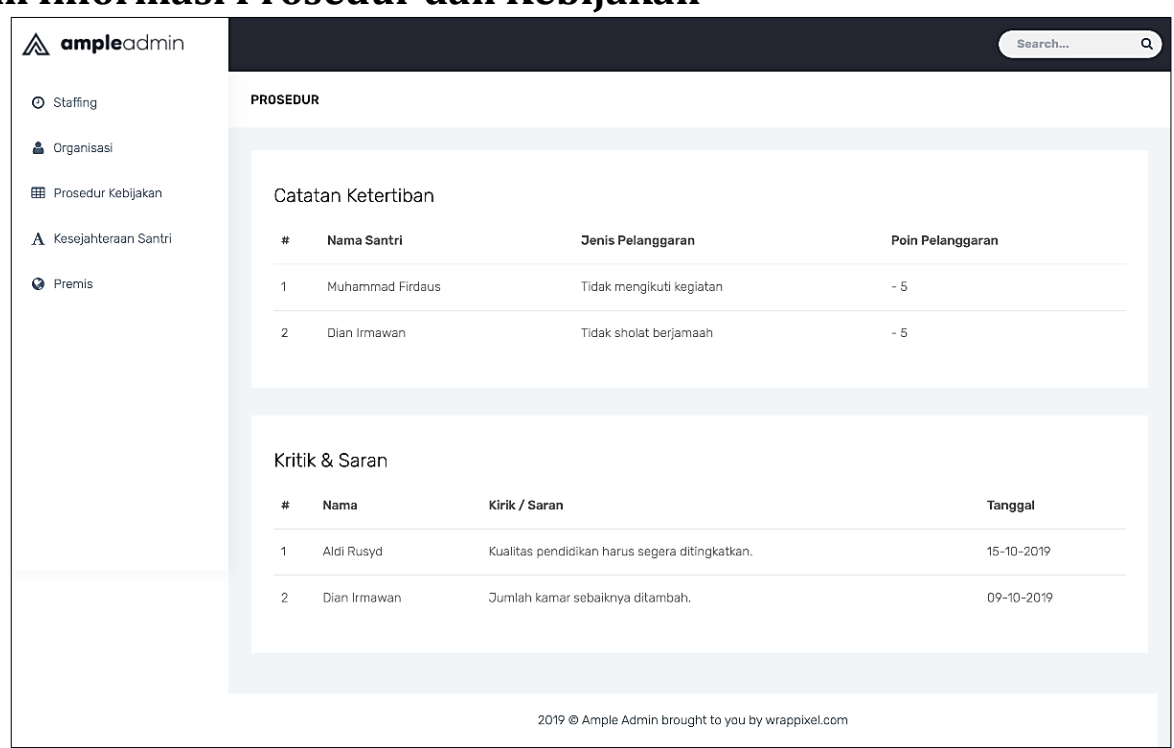

Gambar 9. Tampilan prototype prosedur dan kebijakan 
e) Sistem Informasi Staffing

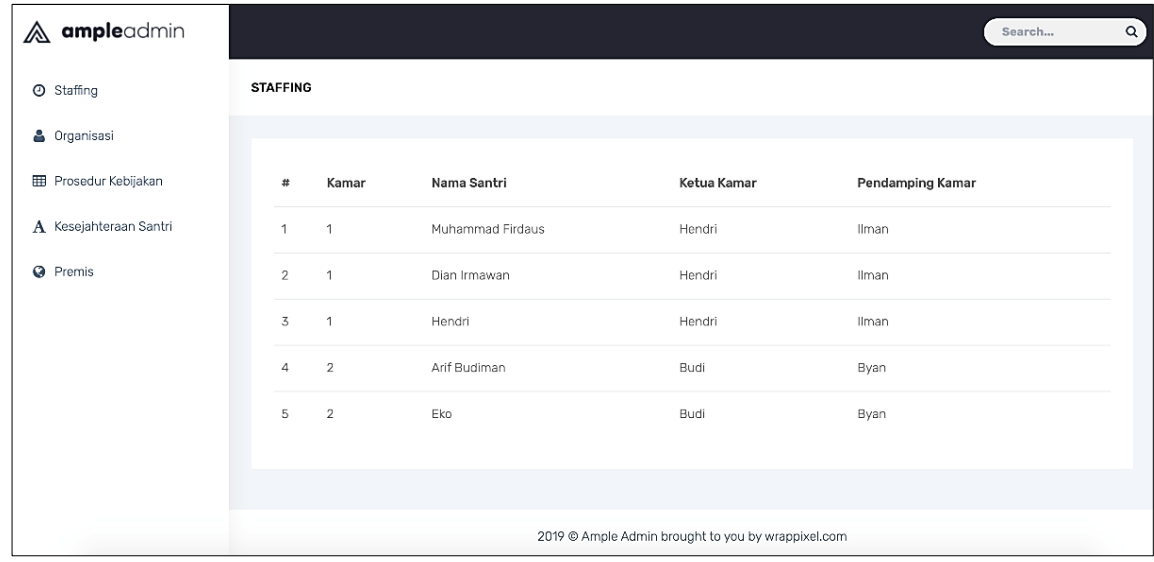

Gambar 10. Tampilan prototype staffing

\section{SIMPULAN}

a) Penerapan artitektur enterprise dengan metode TOGAF ADM dapat di implementasikan dengan baik di dalam perancangan sistem informasi web service boarding school

b) Perancangan Arsitektur yang sudah dilakukan dapat digunakan sebagai pedoman dalam membangun sebuah Sistem Informasi boarding school baru atau dapat juga digunakan dalam integrasi sistem yang sudah ada sehingga proses bisnis yang ada dalam boarding school jauh lebih efektif dan efisien.

\section{DAFTAR PUSTAKA}

[1] Gottschalk, K. 2002. Introduction to Web Services Architecture. IBM System Journal, Vol 41, No 2.

[2] Wirawan, Panji Wisnu, dkk. Integrasi Sistem Informasi Akademik dengan Sistem Monitoring Prestasi Akademik Untuk Pengelolaan Sekolah (Studi Kasus: Mts Taqwal Ilah Dan Yayasan Taqwal Ilah Semarang).

[3] A.A. Gede Yudhi Paramartha, Gusti Ketut Suryaningsih \& Kadek Yota Ernanda Aryanto. 2016. Implementasi Web Service pada Sistem Pengindeksan dan Pencarian Dokumen Tugas Akhir, Skripsi, dan Praktik Kerja Lapangan.

[4] Department for Education, 2015. Boarding School National Minimum Standart. United Kingdom..

[5] Department for Education, 2003. National Minimum Standars for Boarding Schools:Welsh Assembly Government. United Kingdom:Llywodraeth Cynulliad Cymru 